\title{
Cholesterol Metabolism in Human Obesity
}

\author{
Paul J. Nestel, Paul H. Schreibman, and E. H. Ahrens, Jr. \\ From The Rockefeller University, New York 10021
}

A в S T R A C T An experiment was undertaken to test whether in severe obesity cholesterol production rates obtained by isotope kinetic analysis (two-pool compartmental analysis) are comparable to those measured by chemical sterol balance techniques. Eight severely obese but normocholesterolemic patients were studied by the balance method, and five of these eight were studied by compartmental analysis. Cholesterol turnover was $10 \%$ higher by compartmental analysis.

In the entire group of eight patients cholesterol turnover was greater than twice that found previously in nonobese patients studied under similar conditions with bile acids and neutral sterols both participating in the increase. This increment was directly related to excess body fat and to adipose cellularity, with correlation coefficients of 0.66 and 0.72 , respectively. The amount of cholesterol in the slowly turning over pool B was related to degree of adiposity, but that in plasma and in pool A did not differ from values in nonobese patients.

\section{INTRODUCTION}

The turnover of cholesterol has been reported to bear a relationship to body fat $(1,2)$. In a study of 22 subjects of average body build, Nestel, Whyte, and Goodman (1) observed that excess body weight was correlated significantly with the daily production rate of cholesterol and also with the size of that slowly turningover pool of cholesterol that is considered to include the cholesterol in adipose tissue. From this work and that of Miettinen (2) emerged the suggestion that the turnover of cholesterol in adipose tissue might influ-

Portions of this work were presented at the 25th Annual Meeting of the Council on Arteriosclerosis of the American Heart Association, Anaheim, Calif. 1971. Circ. Suppl. 44 : II-1.

Dr. Nestel performed this work while on a FulbrightHays Fellowship. His present address is: Department of Clinical Science, The John Curtin School of Medical Research, The Australian National University, Canberra, Australia.

Received for publication 3 November 1972 and in revised form 15 May 1973. ence total cholesterol turnover, especially in obesity. The absence of a significant relationship between the concentration of cholesterol in plasma and the production rate of body cholesterol (as a function of body weight) demonstrated, furthermore, that an increased rate of cholesterol production need not give rise to hypercholesterolemia.

None of the patients studied by Nestel et al. (1) were markedly obese; indeed, those who were leanest were also the most hypercholesterolemic. In that study, rates of daily cholesterol turnover were measured only by compartmental analysis, a series of calculations that are based on the rate of change in the plasma specific radioactivity curve after a single intravenous injection of radioactive cholesterol. It has been shown that values for cholesterol turnover derived in this way may exceed those obtained by chemical sterol balance techniques by about $15 \%$ in various hyperlipidemic states $(3,4)$. On the other hand, Miettinen's findings of increased cholesterol production in obesity were obtained by sterol balance (2).

Further studies were therefore designed in which cholesterol turnover was measured simultaneously by the two different approaches in a group of markedly obese, normocholesterolemic subjects. Adipose tissue biopsies and total body fat estimations furnished data on adipocyte size and cellularity, as well as concentration and total content of cholesterol in adipose tissue. It was therefore possible to compare total body adipose cholesterol content obtained directly with the cholesterol pool sizes derived by compartmental analyses.

\section{METHODS}

\section{Patients}

Eight obese subjects, six women and two men aged 26-59 $\mathrm{yr}$ with body weights ranging from 182 to $336 \%$ of ideal, were maintained at constant body weights on the metabolic ward of The Rockefeller University Hospital. The oldest patient (no. 6) had an enlarged heart (possibly due to her obesity) and required diuretics to prevent the accumulation of edema. This interfered with assessment of weight changes: there was an initial loss of $5 \mathrm{~kg}$ that was slowly regained during the subsequent 3 mo (the gradual re- 
TABLE I

Various Parameters of Cholesterol Metabolism in Eight Obese Patients

\begin{tabular}{|c|c|c|c|}
\hline Patient & 1 & 2 & 3 \\
\hline Sex; age, $y r$ & $\mathrm{~F} ; 47$ & $\mathrm{~F} ; 49$ & $\mathrm{~F} ; 44$ \\
\hline Body weight $\mathrm{kg} ; \%$ of ideal & $100 ; 190$ & $102 ; 182$ & $120 ; 260$ \\
\hline Caloric requirement, ${ }^{*} \mathrm{cal} / \mathrm{m}^{2} / d a y$ & $2,250(1,136)$ & $2,500(1,202)$ & $2,688(1,250)$ \\
\hline \multicolumn{4}{|l|}{ Duration of metabolic study, $\ddagger$} \\
\hline \multicolumn{4}{|l|}{ Plasma cholesterol, } \\
\hline Cholesterol intake, $m g /$ day & 500 & $\begin{array}{l}218 \pm 17 ; 20 \\
550\end{array}$ & $\begin{array}{l}215 \pm 14 ; 21 \\
590\end{array}$ \\
\hline $\begin{array}{l}\text { Cholesterol absorption, } \S m g ; \% \\
\text { Plasma triglycerides, }\end{array}$ & - & $410 ; 75$ & $360 ; 61$ \\
\hline$m g / 100 m l \pm S D ;$ analyses & $154 \pm 12 ; 12$ & $170 \pm 38 ; 24$ & $133 \pm 21 ; 21$ \\
\hline \multicolumn{4}{|l|}{ Fecal steroids $(g / d a y \pm S D)$} \\
\hline \multicolumn{4}{|l|}{ Neutral } \\
\hline Total & $1.19 \pm 0.19$ & $1.11 \pm 0.09$ & $1.89 \pm 0.25$ \\
\hline Endogenous & - & $0.97 \pm 0.09$ & $1.66 \pm 0.16$ \\
\hline Acidic & $0.58 \pm 0.05$ & $0.61 \pm 0.23$ & $0.64 \pm 0.09$ \\
\hline Total & $1.77 \pm 0.22$ & $1.72 \pm 0.29$ & $2.53 \pm 0.30$ \\
\hline \multicolumn{4}{|l|}{ Chemical balance (synthesis) } \\
\hline (excretion - intake), g/day & 1.27 & 1.17 & 1.94 \\
\hline \multicolumn{4}{|l|}{ Combined balance (turnover) } \\
\hline (endogenous neutral + acidic), $g / d a y$ & 一 & 1.58 & 2.30 \\
\hline $\begin{array}{l}\text { Compartmental Analysis } \\
\text { (production rate }=\text { turnover), } g / \text { day } \\
\% \text { Disagreement }\end{array}$ & - & 1.64 & 2.36 \\
\hline (balance turnover $=100 \%$ ) & 一 & +4 & +3 \\
\hline
\end{tabular}

* To maintain constant body weight.

$\ddagger$ Number of days of successive stool collections and number of 4- or 6-day pools analyzed.

$\S$ Milligrams cholesterol absorbed per day, and percent of daily intake absorbed.

appearance of moderate edema in the legs and over the sacrum during that period made it likely that most of the weight regained was fluid). The maintenance of constant body weight in the other seven subjects, while not as difficult as in patient 6 , was not as easily achieved as in nonobese subjects, and gradual fluctuations (up to $2 \mathrm{~kg}$ ) occurred over periods of about $4 \mathrm{wk}$, especially in two of the heaviest patients. Nevertheless, changes in total food intake were not made after the $3 \mathrm{rd}$ wk, and generally these gradual weight fluctuations disappeared spontaneously; they represented, at most, variations of $1 \%$ of body weight.

\section{Diets}

The patients were maintained solely on liquid formula diets, as developed originally at this Hospital $17 \mathrm{yr}$ ago (5) ; supplements of minerals and vitamins were given (5). All formulas contained $15 \%$ of total calories as milk protein (RI-5, Ross Laboratories, Columbus, Ohio), $45 \%$ as glucose and $40 \%$ as fat (cottonseed oil, containing 2.97 mg $\beta$-sitosterol/g of oil). Crystalline cholesterol (Mann Research Labs., Inc., New York) was dissolved in the oil during the preparation of the formula; in this way, each 1,000 calories of formula provided $220 \mathrm{mg}$ of cholesterol and $238 \mathrm{mg}$ of $\beta$-sitosterol. Each patient received $300 \mathrm{mg}$ chromic oxide daily in five divided doses as a marker for variations in fecal flow.

The patients' weights were maintained constant (as qualified above) on this diet for the 3 mo required by this study. This was followed by a long period of weight loss, the first $3 \mathrm{wk}$ of which were included in the present study; during that short period, the formula furnished only $20 \%$ of the previous caloric intake. By enriching the formula with additional cholesterol, the daily intake of cholesterol for each patient was maintained at the same level as during the preceding 3-mo period.

\section{Isotopic cholesterol}

To 5 of 8 patients a single intravenous dose of $\left[4-{ }^{14} \mathrm{C}\right]-$ cholesterol or $\left[1,2{ }^{3} \mathrm{H}\right]$ cholesterol (The Radiochemical Centre, Amersham, England), $60-100 \mu \mathrm{Ci}$, was administered. These materials were first subjected to thin-layer chromatography on Silica Gel $\mathrm{H}$ plates with a moving phase of ethyl ether-heptane $45: 55$ ( $\mathrm{vol} / \mathrm{vol})$. At least $95 \%$ of the radioactivity moved at the same rate as a pure cholesterol standard. Known amounts of isotopic sterol from this band were then dissolved in $1 \mathrm{ml}$ ethanol and dispersed in $150 \mathrm{ml}$ of $0.15 \mathrm{M}$ sodium chloride before intravenous infusion. After administration, the bottle and tubing were washed with absolute ethanol for assay of adherent radioactive isotope (in all cases this was less than $1 \%$ of the total dose). 
Obtained by Sterol Balance Methods and by Compartmental Analysis

\begin{tabular}{|c|c|c|c|c|c|}
\hline 4 & 5 & 6 & 7 & 8 & $\begin{array}{l}\text { All patients } \\
(\text { mean } \pm S D)\end{array}$ \\
\hline$F ; 26$ & $\mathrm{~F} ; 46$ & $\mathrm{~F} ; 59$ & $\mathrm{M} ; 33$ & $\mathrm{M} ; 48$ & \\
\hline $123 ; 211$ & $147 ; 295$ & $150 ; 310$ & $175 ; 271$ & $212 ; 336$ & $141 ; 257$ \\
\hline $3,156(1,355)$ & $3,281(1,414)$ & $3,094(1,279)$ & $4,388(1,596)$ & $4,375(1,498)$ & $3,355(1,371)$ \\
\hline $28 ; 6$ & $40 ; 10$ & $40 ; 9$ & $42 ; 10$ & $28 ; 7$ & \\
\hline $127 \pm 10 ; 17$ & $185 \pm 12 ; 20$ & $194 \pm 14 ; 24$ & $171 \pm 11 ; 25$ & $182 \pm 9 ; 27$ & $182 \pm 10$ \\
\hline 690 & 720 & 680 & 960 & 960 & 706 \\
\hline- & $420 ; 58$ & $440 ; 65$ & $510 ; 53$ & - & $428 ; 63$ \\
\hline $88 \pm 9 ; 16$ & $121 \pm 15 ; 18$ & $125 \pm 20 ; 24$ & $184 \pm 21 ; 22$ & $127 \pm 20 ; 22$ & $138 \pm 30$ \\
\hline $2.06 \pm 0.45$ & $2.37 \pm 0.45$ & $1.48 \pm 0.19$ & $1.74 \pm 0.27$ & $2.46 \pm 0.55$ & $1.79 \pm 0.18$ \\
\hline - & $2.07 \pm 0.49$ & $1.26 \pm 0.07$ & $1.29 \pm 0.27$ & & \\
\hline $0.36 \pm 0.07$ & $0.60 \pm 0.12$ & $0.45 \pm 0.11$ & $1.14 \pm 0.32$ & $1.00 \pm 0.09$ & $0.67 \pm 0.09$ \\
\hline $2.42 \pm 0.41$ & $2.97 \pm 0.48$ & $1.93 \pm 0.25$ & $2.88 \pm 0.57$ & $3.46 \pm 0.59$ & $2.46 \pm 0.22$ \\
\hline 1.73 & 2.25 & 1.25 & 1.92 & 2.50 & $1.75 \pm 0.49$ \\
\hline - & 2.67 & 1.71 & 2.43 & - & $2.13 \pm 0.47$ \\
\hline - & 3.37 & 1.88 & 2.61 & - & $2.37 \pm 0.68$ \\
\hline - & +26 & +10 & +7 & - & $+10.0 \pm 9.0$ \\
\hline
\end{tabular}

\section{Analytical procedures}

Collections of total fecal output were combined into 4day pools (or 6-day collections when subjects were constipated). In this way, 6-10 consecutive analyses were obtained in each patient with the exception of no. 1, who withdrew from the study after only four 4-day pools had been obtained. Fecal neutral and acidic steroids were isolated quantitatively, and their mass and radioactivity measured as described previously $(6,7)$. These techniques permit the critical distinction to be made between plant sterols and cholesterol and between the bacterial conversion products derived from these two sources during intestinal transit. Corrections of neutral steroid excretion for unexplained losses during intestinal transit were made with dietary $\beta$-sitosterol as an internal standard; variations in fecal flow of bile acids were corrected with chromic oxide as internal standard (8). The calculations employed and the rationale underlying the use of these internal standards have been presented elsewhere (3).

Plasma cholesterol and triglyceride concentrations were measured by automated techniques $(9,10)$ and radioactivity by scintillation counting. Aspirations of subcutaneous adipose tissue were performed from the buttocks: adipocytes were sized and counted by the method of Hirsch and Gallian (11). Cholesterol concentration of adipose tissue was determined after extractior. and saponification using the autoanalyzer method employed for plasma samples.

\section{Calculations}

Cholesterol synthesis and turnover. Daily synthesis rates were determined by the chemical sterol balance techniques introduced in this laboratory (Eq. 9 of reference 3 ). Rates of daily turnover were calculated in two ways: by the sum of daily endogenous fecal steroids (acidic and neutral) measured by sterol balance techniques (Eq. 12 of reference 3 ) and by compartmental analysis of specific activity-time curves of plasma cholesterol after a single dose of radioactive cholesterol according to the two-pool model of Goodman and Noble (12) as extended by Nestel et al. (1). Absorption of cholesterol. Cholesterol absorption measurements were made in the five patients to whom a single intravenous dose of radioactive cholesterol was given; calculations were made by method I of reference 3 in which the difference between intake and unabsorbed dietary cholesterol is ascribed to absorption. Comparisons between this and four other methods for measuring cholesterol absorption have recently been published by this laboratory (13).

Ideal weights and total body fat. Ideal body weight estimates were obtained from Metropolitan Life Insurance Company tables (14). Lean body mass was calculated as $82 \%$ of ideal body weight (15); the figure for lean mass was subtracted from the actual body weight to obtain the total mass of body fat. In patients 7 and 8 total body fat also was measured according to Pace and Rathburn (16) 
TABLE II

Cholesterol Synthesis by Balance Methods: Comparison of Obese with Nonobese Patients

\begin{tabular}{lccc} 
& Obese & & Nonobese \\
\hline Authors & Present* & Connor et al. $\neq$ & Grundy and Ahrens \\
Number of Patients & 8 & 6 & 9 \\
Dietary cholesterol, $m g / d a y$ & 706 & 0 & Variable $\|$ \\
Fecal steroids, $m g /$ day & & 489 & 546 \\
$\quad$ Total neutral & 1,790 & 426 & 319 \\
Acidic & 670 & 915 & 865 \\
Total excretion minus intake (= daily synthesis) & 1,754 & & \\
\hline
\end{tabular}

* Liquid formula diets with $40 \%$ of total calories as cottonseed oil.

$\ddagger$ Healthy normolipidemic males on cholesterol-free liquid formula diets with $40 \%$ of total calories as redistilled corn oil (Table IV of reference 17).

$\S$ Hyperlipidemic men and women on liquid formula diets with $40 \%$ of total calories as redistilled corn oil (mean of periods II and III, Table IV of reference 18).

|| Diets contained cholesterol in varying amounts. The neutral steroid is endogenous only. Excretion represents sterol turnover rather than synthesis.

after intravenous administration of $100 \mu \mathrm{Ci}{ }^{3} \mathrm{H}_{2} \mathrm{O}$; in both cases the values obtained agreed within $10 \%$ with those obtained by the ideal body weight calculations.

\section{RESULTS}

Absorption, synthesis, and turnover of cholesterol. Table I presents the sterol balance data obtained in this group of eight obese patients, from which daily synthesis rates were calculated by subtracting the daily cholesterol intake from the daily excretion of total fecal steroids. (The justification for this calculation has been presented elsewhere in detail [3].) It is seen that the mean synthesis rate was $1.75 \mathrm{~g} /$ day (range 1.17-2.50).

All eight patients in the present study were maintained on cholesterol-containing diets, but absorption data could be obtained only in those five to whom radioactive cholesterol had been administered. Table I shows that the mean absorption of dietary cholesterol was $63 \%$ (range $53-75 \%$ ), a figure that is appreciably higher than that previously obtained in nonobese patients (13).

By compartmental analysis we calculated daily cholesterol turnover to average $2.37 \mathrm{~g} /$ day (range 1.64 $3.37)$; the daily turnover rate obtained by the sterol balance method averaged $2.13 \mathrm{~g}$ /day (range 1.58-2.67). Thus, the mean turnover rate by compartmental analysis was $10 \%$ higher than that obtained by the sterol balance method. In a previous study of nonobese patients we noted that use of the two-pool model gave daily turnovers averaging $15 \%$ higher than turnover rates simultaneously performed by sterol balance methods (3).

Samuel, Holtzman, Meilman, and Perl (19) suggested that this discrepancy was largely due to overestimation by the two-pool calculation; when a three- pool model or Perl and Samuel's input-output model (20) are used, turnover data by isotope kinetics closely match those obtained by sterol balance methods (DeW. S. Goodman, personal communication; P. Samuel, personal communication). Further reasons for this discrepancy might include loss of cholesterol from the skin surface and in the urine as corticosteroids. Bhattacharyya, Connor, and Spector (21), have reported that about $100 \mathrm{mg}$ cholesterol is shed daily from the skin, half of which appears to be derived from plasma (T. Nikkari, personal communication). The amount of plasma cholesterol converted to adrenal steroids is of a similar order of magnitude (22).

Table II compares the present data on daily cholesterol synthesis in 8 obese patients with data derived by the same methods and under similar experimental conditions in two laboratories in 15 nonobese patients. The daily synthesis rate of $1.75 \mathrm{~g} /$ day was twice that found in nonobese patients. The main increment in fecal steroid excretion in the obese appeared in the neutral fraction, but there was also a small increase in bile acid excretion.

Estimates of cholesterol pool sizes. The specific activity-time curves of plasma cholesterol could be clearly resolved into two rate constants $(\alpha \text { and } \beta)^{1}$ (Fig. 1), as previously demonstrated in nonobese patients (1,

${ }^{1}$ Abbreviations used in this paper: a, constant for pool A with $\mathrm{t}_{1}=$ half-life; $\beta$, constant for pool $\mathrm{B} ;-K_{\mathbf{A A}}$, rate constant for total removal of cholesterol from pool A. $-K_{B B}$, rate constant for total removal of cholesterol from pool B; $M_{A}$, mass of size of pool A; $M_{B}$, mass of size of pool B; $\bar{M}_{B}$, mean of $M_{B}$ min and the maximum limit case for mass of pool B. The latter assumes that all of the cholesterol produced in pool A is derived from dietary absorption; $M_{B}$ min, extreme limit case for smallest possible mass in pool B which assumes that there is no syn- 
12). These rate constants describe the wide difference in turnover rates of two main pools, A and B. The masses of the two pools are given by $M_{A}$ and $M_{B}$ : the latter is an approximation, being the mean of the two possible extremes for $\bar{M}_{B}(1)$. These values are listed in Table III. Two-pool compartmental analysis has been described in detail by others $(1,12,19)$.

Comparing these parameters in five obese patients with those previously described in nonobese patients (Table IV), we see that the major difference lies in the estimated size of pool $\mathrm{B}$. The size of $\bar{M}_{B}$ which may include much of the adipose cholesterol, was greatly enlarged in the obese, while that of $M_{A}$ was not. Although the rate constant for the movement of cholesterol from pool $\mathrm{B}\left(-K_{B B}\right)$ was reduced, the total turnover of cholesterol within pool B would certainly not be decreased in the obese subjects because of the much greater mass in that pool. Recent studies by Goodman, Noble, and Dell (personal communication) and by Lieberman and Samuel (personal communication), in which decay curves of approximately 1-yr duration were obtained, indicate that $\bar{M}_{B}$ and $M_{B}$ min are much underestimated when decay curves of short duration (as in the present study) are analyzed. Thus, it is likely that our figures in Table III for $\bar{M}_{B}$ and in Table IV for $M_{B}$ min are considerably lower than might have been obtained, had these curves been drawn out to $40 \mathrm{wk}$ or more.

Cholesterol in adipose tissuc. A few measurements of cholesterol specific activity in adipose tissue were made at irregular times along the plasma specific activity-time curve. These and later data obtained in other nonobese patients indicated a slow increase in adipose specific activity, with values crossing those in plasma at $4-7 \mathrm{wk}$ and remaining higher for many months thereafter. These observations suggest that

thesis in pool $\mathrm{B} ; \mathrm{PR}_{A}$, cholesterol production rate or turnover in pool A which includes both synthesis and dietary absorption.

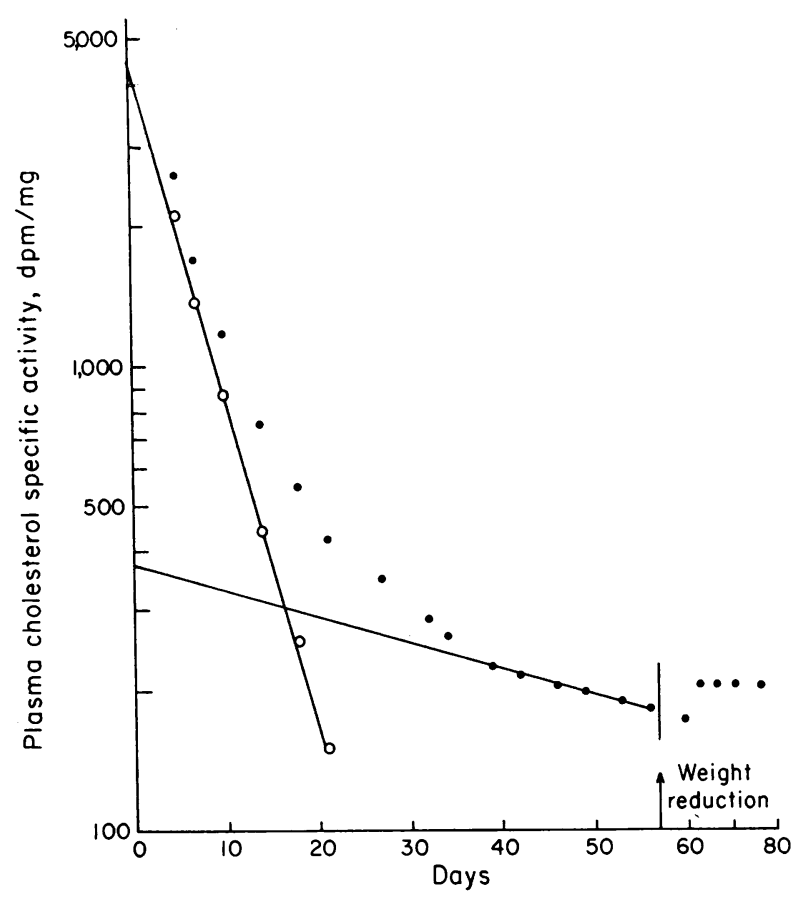

Figure 1 Semilogarithmic plot of plasma cholesterol specific activity vs. time in days in a typical obese patient (no. 3, Table I). $\alpha$ and $\beta$ designate rate constants for the readily miscible pool $A$ and slowly miscible pool $B$, respectively. Body weight and caloric intake remained constant through 57 days of study at which time caloric intake was reduced by $80 \%$. Note the sudden rise in the decay curve when weight reduction began.

equilibration between plasma and adipose cholesterol took place only very slowly.

The size and cholesterol content of adipocytes taken from five obese patients are listed in Table V. Cell size was enlarged in all (slightly less than twofold), and total cell number was greatly increased (two- to fourfold). The cholesterol concentration of subcutaneous adipose tissue multiplied by the estimated total body fat content gave calculated values for total adipose tissue

TABLE III

Two-Pool Compartmental Analyses in Fiv' Obese Patients

\begin{tabular}{|c|c|c|c|c|c|c|c|c|c|c|c|}
\hline \multirow[b]{2}{*}{ Patient } & \multicolumn{2}{|c|}{$\alpha$} & \multicolumn{2}{|c|}{$\beta$} & \multirow[b]{2}{*}{$-K_{A A}$} & \multirow[b]{2}{*}{$-K_{B B}$} & \multirow[b]{2}{*}{$M_{A}$} & \multirow[b]{2}{*}{$M_{B} \min$} & \multirow[b]{2}{*}{$\bar{M}_{B}$} & \multirow[b]{2}{*}{$\mathrm{PR}_{A}$} & \multirow{2}{*}{$\begin{array}{c}\text { Cholesterol } \\
\text { turnover* }\end{array}$} \\
\hline & $\mathrm{t}_{\frac{1}{2}}$ & & $t_{\frac{1}{3}}$ & & & & & & & & \\
\hline & days & $d a y^{-1}$ & days & $d a y^{-1}$ & $d a y^{-1}$ & $d a y^{-1}$ & $g$ & $g$ & $g$ & $g / d a y$ & $g / d a y$ \\
\hline 2 & 5.5 & 0.126 & 46 & 0.0150 & 0.111 & 0.030 & 26.1 & 44.4 & 64.6 & 1.64 & 1.58 \\
\hline 3 & 4.0 & 0.173 & 54 & 0.0128 & 0.161 & 0.025 & 26.6 & 77.7 & 119.3 & 2.36 & 2.30 \\
\hline 5 & 4.0 & 0.173 & 43 & 0.0160 & 0.164 & 0.025 & 30.3 & 65.4 & 126.7 & 3.37 & 2.67 \\
\hline 6 & 4.3 & 0.161 & 42 & 0.0165 & 0.146 & 0.032 & 22.5 & 44.3 & 68.3 & 1.88 & 1.71 \\
\hline 7 & 4.5 & 0.154 & 52 & 0.013 .3 & 0.141 & 0.027 & 34.1 & 82.0 & 123.2 & 2.61 & 2.43 \\
\hline Mean & 4.5 & 0.157 & 47.4 & 0.0147 & 0.145 & 0.023 & 27.9 & 62.8 & 100.4 & 2.37 & 2.13 \\
\hline$\pm \mathrm{SEM}$ & \pm 0.3 & \pm 0.008 & \pm 2.4 & \pm 0.0007 & \pm 0.009 & \pm 0.001 & \pm 1.9 & \pm 8.0 & \pm 13.9 & \pm 0.30 & \pm 0.21 \\
\hline
\end{tabular}

* Cholesterol turnover as determined by the combined balance method, Eq. 12 of reference 3. 
TABLE IV

Comparison of Compartmental A nalyses in Obese and Nonobese Patients

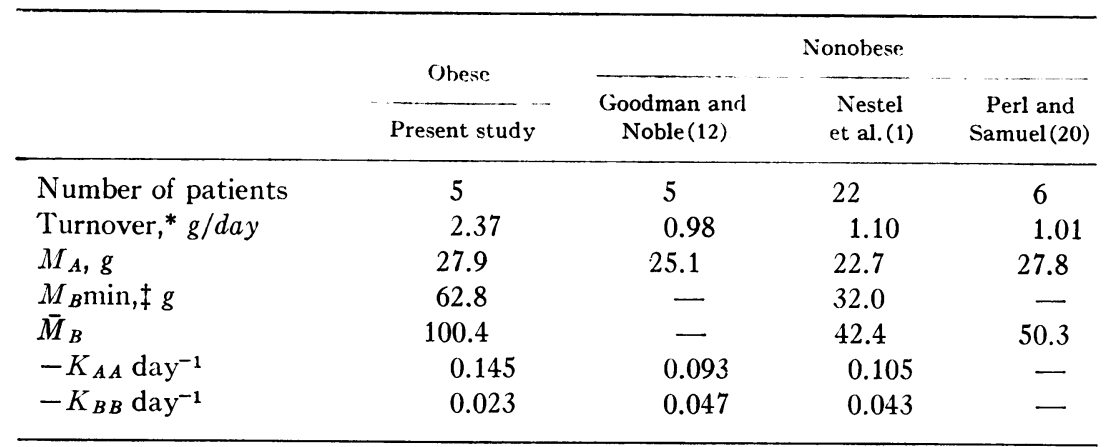

* Turnover is synonomous with $\mathrm{PR}_{A}(1,12)$ and $I_{T}$ (total input) (20).

$\ddagger$ In the present study, $\bar{M}_{B}=$ mean of extreme limit cases, $M_{B} \min$ and $M_{B}$ max, i.e. $M_{B}$ min assumes $S_{B}=0$, and $M_{B}$ max assumes that $S_{A}=$ absorbed dietary cholesterol only. Nestel et al. based $\bar{M}_{B}$ on regression analysis assuming body weight $=60 \mathrm{~kg}$ and plasma cholesterol $=200 \mathrm{mg} / 100 \mathrm{ml}$. Perl and Samuel calculated $\bar{M}_{B}$ as the total exchangeable cholesterol $-M_{A}$.

cholesterol content. These calculated values are compared to those derived by isotope kinetic analysis for the slowly turning-over cholesterol pool $\left(\bar{M}_{B}\right)$. The larger mass obtained by direct analysis in all cases might have suggested the existence in obesity of a very slowly exchanging cholesterol pool not accounted for by two-pool compartmental analysis, were we not aware that the figures for $\bar{M}_{B}$ are undoubtedly underestimates (see discussion of Tables III and IV above).

Increases in cholesterol synthesis obtained by the sterol balance method correlated well with excess body weight and total adipose cellularity (Fig. 2).

Effects of weight loss. Weight loss occurred rapidly when the caloric intake was reduced by $80 \%$. A uniform finding was the rise in the specific activity of plasma cholesterol during weight reduction (Fig. 1) that persisted throughout the 3 wk of observation.
During this short period of weight losing, levels of plasma cholesterol rose slightly in three patients and remained unchanged in four patients.

\section{DISCUSSION}

Nestel et al. (1) first observed a relationship between cholesterol turnover and excess body weight in studies relying solely upon compartmental analysis. More recently, Miettinen (2) has reached similar and more extended conclusions using the sterol balance method: he found that obese normolipidemic and hypertriglyceridemic patients had greater fecal excretion of total steroids than lean controls, indicating higher rates of cholesterol synthesis. The present study compares the two methods (compartmental analysis and sterol balance) carried out simultaneously in markedly obese patients: close agreement was obtained for cholesterol

TABLE V

Adipocyte Size, Number, and Cholesterol Content

\begin{tabular}{|c|c|c|c|c|c|c|}
\hline Patient & Normals & 2 & 3 & 5 & 6 & 7 \\
\hline \multicolumn{7}{|l|}{ Adipocyte } \\
\hline Size, $\mu g$ lipid/cell & $0.665^{*}$ & 1.086 & 1.050 & 1.170 & 1.205 & 1.142 \\
\hline Number, $1 \times 10^{9}$ & $26.8^{*}$ & 52.5 & 79.0 & 90.6 & 95.4 & 106.9 \\
\hline \multicolumn{7}{|l|}{ Adipose cholesterol } \\
\hline concentration, $\mathrm{mg} / \mathrm{g}$ lipid & $1.75 \ddagger$ & 1.50 & 1.50 & 1.50 & 1.85 & 1.12 \\
\hline Total body fat, $\S \mathrm{kg}$ & - & 57 & 83 & 106 & 115 & $122 \|$ \\
\hline Content, $g$ & 31.2 & 85.50 & 124.50 & 159.00 & 212.75 & 136.64 \\
\hline $\bar{M}_{B}, g$ & $42.4 ף$ & 64.58 & 119.30 & 126.71 & 68.32 & 123.15 \\
\hline
\end{tabular}

* Personal communication, Dr. J. Hirsch.

$\ddagger$ Personal communication, Dr. John Crouse.

$\S$ Total body fat $=$ actual body weight $-(0.82 \times$ ideal body weight $)$.

$\|$ Total body fat calculated by ${ }^{3} \mathrm{H}_{2} \mathrm{O}$ dilution $=148 \mathrm{~kg}$.

I Nestel et al. (1). 
turnover. The $10 \%$ larger turnover obtained by twopool compartmental analysis is probably an overestimate as suggested by Samuel and co-workers (19, 20), hecause the late third exponential is not considered in kinetic studies of only 3 mo duration. On the other hand, losses of cholesterol from the skin (21) and of corticosteroids in the urine (22) are not included in the sterol balance method. We considered it important to make this comparison of turnover rates by two independent methods, due to the uncertainties characteristic of each method, i.e. the question of isotopic equilibrium, on the one hand, and of attainment of the metabolic steady state, on the other (3). It is possible that when cholesterol turnover is increased, improved agreement between sterol balance and compartmental analysis is brought about by the increased turnover in pool $\mathrm{A}$, thus minimizing the error incurred by omitting the third pool from the calculation. Aimost complete agreement between the two methods was obtained when sterol turnover was stimulated with a bile-sequestering resin, in contrast with a discrepancy of up to $25 \%$ during the pretreatment period (N. E. Miller, P. J. Nestel, P. Clifton-Bligh, unpublished observations).

Thus, the present data confirm the previous findings of increased cholesterol turnover in obesity: in eight very obese patients the mean daily synthesis rate was double that previously measured in lean patients. There was also general agreement with the regression equation calculated by Nestel et al. (1) in that the production rates (Table III) of 1.64, 2.36, 3.37, 1.88, and $2.61 \mathrm{~g} /$ day correspond to predicted values of $1.98,2.42$, $2.82,2.93$, and 3.30 , respectively. Moreover, the mean pool $\mathrm{B}$ values of $65,119,127,68$, and $123 \mathrm{~g}$ calculated herein correspond to predicted masses of 78, 96, 114, 118 , and $132 \mathrm{~g}$, respectively. This suggests that, with respect to cholesterol metabolism, obese subjects represent an extension of the normal weight population. The discrepancies noted in patient 6 may have been due to her older age and mild cardiac decompensation.

The present balance studies were carried out in patients fed cholesterol-containing diets, and so a decreased absorption rate might account for increased excretion. However, cholesterol absorption in these patients averaged $63 \%$, a value that is somewhat higher than previously reported in normal weight patients (13).

The site of increased cholesterol synthesis in these obese patients is of major interest, especially as the size of pool A was not increased. The plasma cholesterol concentrations were also low as is often seen in normolipidemic patients consuming diets rich in polyunsaturated fats. The metabolic clearance rate (fraction of plasma "cleared" per day) was $23 \%$ for five obese patients; this is identical to that found in normocholes-
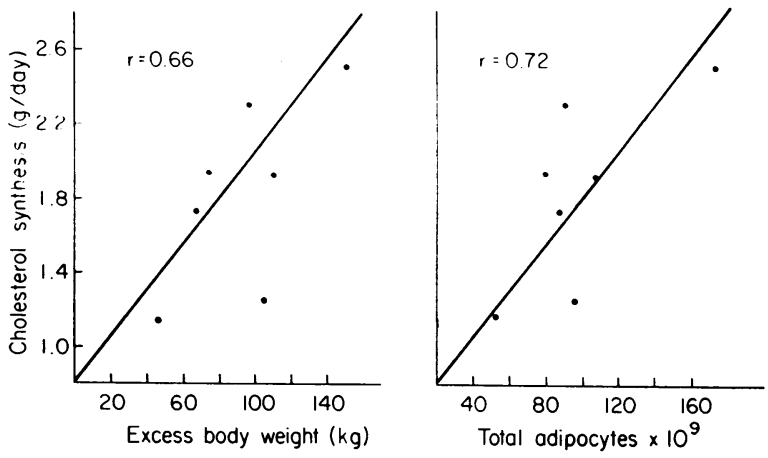

FIgURE 2 Relationship between daily cholesterol synthesis, excess body weight, and adipose cellularity in seven obese patients. Synthesis = chemical balance data; excess body weight $=$ actual - ideal body weight $;$ adipose cellularity $=$ total body fat $\div$ mean adipocyte size.

terolemic patients of normal weight (1). We conclude then that plasma cholesterol concentrations do not necessarily reflect cholesterol synthesis rates. This has been reported previously under other conditions such as treatment with cholestyramine (4) or disturbances of the small bowel (23). By contrast, elevated plasma cholesterol (presumably a part of pool A) when associated with type IIa hyperlipoproteinemia is often associated with a low cholesterol or bile acid turnover (1, $24,25)$.

The compartmental data show an increased pool B in obesity and raise the possibility that the overall increase in cholesterol turnover might reflect synthesis in adipose tissue, a tissue in which cholesterol turns over more slower than in liver or intestine. However, in vitro measurement of sterol biosynthesis rates from glucose in human adipose tissue are quite low (P. H. Schreibman, unpublished observations, averaging less than 1 $\mathrm{mg}$ cholesterol $/ \mathrm{kg}$ body fat/day, (although in vitro findings need not apply in the intact patient). As seen in Fig. 2, total body cholesterol synthesis is significantly correlated with both excess body weight and adipose cellularity. It is however quite possible that all of the excess synthesis is occurring in pool A (i.e., liver or intestine) under some influence of the enlarged adipose organ and the changes in hormonal balance that accompany obesity. For example, the known increased flux of free fatty acids in obesity (26) may provide more acetyl CoA precursor for cholesterologenesis. ${ }^{2}$

${ }^{2}$ If free fatty acid turnover is $900 \mu \mathrm{mol} / \mathrm{min}$ (and can be much higher in obesity [26]) and all 16 carbons of palmitate are incorporated into the cholesterol (27 carbons), then this would approximate $693 \mathrm{mM}$ cholesterol/day $(480 \mu \mathrm{M} / \mathrm{min}$ $\times 60 \times 24 \mathrm{~h}$ ), or $268 \mathrm{~g} /$ day. If only $1 \%$ of the free fatty acid turnover is available for sterol biosynthesis, then 2.68 $g$ cholesterol can still be derived from this substrate. 
The calculation of $\bar{M}_{B}$ (cholesterol mass in pool B) is almost certainly in error. Indeed, if a third slower exponential had been demonstrated by carrying the decay curve out to about 40 wk (19), then the total miscible pool of cholesterol would have been found to be much larger than that shown in Table III. With these reservations in mind, it is nevertheless interesting to compare our $\bar{M}_{B}$ data with the measured adipose cholesterol content. As seen in Table V, adipose tissue can account for much of the expanded $\bar{M}_{B}$ in these five obese patients. The agreement between these two sorts of calculation is surprisingly good, considering possible regional differences in adipocyte size, cholesterol concentration, or errors in total body fat estimation.

Finally, a rise in plasma cholesterol specific activity with weight reduction was seen in all five patients while consuming a diet containing cholesterol in amounts equivalent to their weight maintenance regimes in confirmation of Miettinen's observations (27) which was seen even when plasma cholesterol concentrations rose. We believe that these findings suggest a net efflux of more richly labeled cholesterol from the shrinking adipose tissue mass; Samuel, Perl, Holtzman, Rochman, and Lieberman have also noted higher specific activities in this tissue than in plasma, after administering radioactive cholesterol intravenously, in a nonobese hypercholesterolemic patient (28).

\section{ACKNOWLEDGMENTS}

We are grateful to Mrs. Barbara Good, Mrs. Eleanor Mathusek, Mrs. Stephanie Tonner, Miss Susan Turner, Albert Angevin, and Fred Rubel for their excellent technical assistance.

This study was supported in part by U. S. Public Health Service Grant no. HL-06222 from the National Heart and Lung Institute, and by U. S. Public Health Service Grant no. FR-00102 from the General Clinical Research Centers Branch of the Division of Research Resources.

\section{REFERENCES}

1. Nestel, P. J., H. M. Whyte, and DeW. S. Goodman. 1969. Distribution and turnover of cholesterol in humans. J. Clin. Invest. 48: 982.

2. Miettinen, T. A. 1971. Cholesterol production in obesity. Circulation. 44 : 842.

3. Grundy, S. M., and E. H. Ahrens, Jr. 1969. Measurements of cholesterol turnover, synthesis, and absorption in man, carried out by isotope kinetic and sterol balance methods. J. Lipid Res. 10: 91.

4. Grundy, S. M., E. H. Ahrens, Jr., and G. Salen. 1971. Interruption of the enterohepatic circulation of bile acids in man: comparative effects of cholestyramine and ileal exclusion on cholesterol metabolism. J. Lab. Clin. Med. 78: 94.
5. Ahrens, E. H., Jr. 1970. The use of liquid formula diets in metabolic studies: 15 years' experience. Adv. Metab. Disord. $4: 297$.

6. Miettinen, T. A., E. H. Ahrens, Jr., and S. M. Grundy. 1965. Quantitative isolation and gas-liquid chromatographic analysis of total dietary and fecal neutral steroids. J. Lipid Res. 6: 411.

7. Grundy, S. M., E. H. Ahrens, Jr., and T. A. Miettinen. 1965. Quantitative isolation and gas-liquid chromatographic analysis of total fecal bile acids. J. Lipid Res. 6: 397.

8. Davignon, J., W. J. Simmonds, and E. H. Ahrens, Jr. 1968. Usefulness of chromic oxide as an internal standard for balance studies in formula-fed patients and for assessment of colonic function. J. Clin. Invest. 47: 127.

9. Block, W. D., K. J. Jarret, Jr., and J. B. Levine. 1965. Use of a single color reagent to improve the automated determination of serum total cholesterol. Autom. Anal. Chem. Tech. Symp. 345.

10. Kessler, G., and H. Lederer. 1965. Fluorometric measurement of triglycerides. Autom. Anal. Chem. Tech. Symp. 341.

11. Hirsch, J., and E. Gallian. 1968. Method for the determination of adipose cell size in man and animals. $J$. Lipid Res. 9: 110.

12. Goodman, DeW. S., and R. P. Noble. 1968. Turnover of plasma cholesterol in man. J. Clin. Invest. 47: 231.

13. Quintão, E., S. M. Grundy, and E. H. Ahrens, Jr. 1971. An evaluation of four methods for measuring cholesterol absorption by the intestine in man. J. Lipid Res. 12: 221.

14. New weight standards for men and women. 1959. Stat. Bull. Metrop. Life Insur. Co. $40: 1$.

15. Diem, K., editor. 1962. Documenta Geigy, Scientific Tables. Geigy Chemical Corp., Ardsley, N. Y. 6th edition. 516.

16. Pace, N., and E. N. Rathburn. 1945. Studies on body composition. III. The body water in chemically combined nitrogen content in relation to fat content. J. Biol. Chem. 158: 685 .

17. Connor, W. E., D. T. Witiak, D. B. Stone, and M. O. Armstrong. 1969. Cholesterol balance and fecal neutral steroid and bile acid excretion in normal men fed dietary fats of different fatty acid composition. J. Clin. Invest. 48: 1363 .

18. Grundy, S. M., and E. H. Ahrens, Jr. 1970. The effects of unsaturated dietary fats on absorption, excretion, synthesis, and distribution of cholesterol in man. J. Clin. Invest. $49: 1135$.

19. Samuel, P., C. M. Holtzman, E. Meilman, and W. Perl. 1968. Effect of neomycin on exchangeable pools of cholesterol in the steady state. J. Clin. Invest. 47: 1,806.

20. Perl, W., and P. Samuel. 1969. Input-output analysis for total input rate and total traced mass of body cholesterol in man. Circ. Res. 25: 191.

21. Bhattacharyya, A. K., W. E. Connor, and A. A. Spector. 1972. Excretion of sterols from the skin of normal and hypercholesterolemic humans. Implication for sterol balance studies. J. Clin. Invest. 51: 2060.

22. Borkowski, A., C. Delacroix, and S. Levin. 1972. Metabolism of adrenal cholesterol in man. I. In vivo studies. J. Clin. Invest. 51 : 1664.

23. Moore, R. B., I. D. Frantz, Jr., and H. Buchwald. 1969. Changes in cholesterol pool size, turnover rate and fecal bile acid and sterol excretion after partial 
ileal bypass in hypercholesteremic patients. Surgery. 65 : 98.

24. Miettinen, T. A. 1970. Detection of changes in human cholesterol metabolism. Ann. Clin. Res. 2: 300.

25. Kottke, B. A. 1969. Differences in bile acid excretion: primary hypercholesterolemia compared to combined hypercholesterolemia and hypertriglyceridemia. Circulation. $40: 13$.

26. Nestel, P. J., and H. M. Whỳte. 1968. Plasma free fatty acid and triglyceride turnover in obesity. Metab. (Clin. Exp.). 17: 1122 .

27. Miettinen, T. A. 1968. Fecal steroid excretion during weight reduction in obese patients with hyperlipidemia. Clin. Chim. Acta. 19: 341.

28. Samuel, P., W. Perl, C. M. Holtzman, N. D. Rochman, and S. Lieberman. 1973. Long-term kinetics of serum and xanthoma cholesterol radioactivity in patients with hypercholesterolemia. J. Clin. Ini'est. 51 : 266. 